\title{
Cognitive-Behavioral Therapy for College Students With ADHD: Temporal Stability of Improvements in Functioning Following Active Treatment
}

By: Arthur D. Anastopoulos, Kristen A. King, Laura H. Besecker, Sarah R. O'Rourke, Allison C. Bray, Andrew J. Supple

Anastopoulos, A.D. King, K.A., Besecker, L.H., O’Rourke, S.R., Bray, A.C., \& Supple, A.J. (2020). Cognitive-behavior therapy for college students with ADHD: Temporal stability of improvements in functioning following active treatment. Journal of Attention Disorders, 24, 863-874. https://doi.org/10.1177/1087054717749932

Made available courtesy of Sage Publications: https://doi.org/10.1177/1087054717749932

***@) The authors. Reprinted with permission. No further reproduction is authorized without written permission from Sage Publications. This version of the document is not the version of record. Figures and/or pictures may be missing from this format of the document. $* * *$

\begin{abstract}
:
Objective: This study examined the extent to which college students with ADHD continued to benefit from a cognitive behavioral therapy (CBT) program beyond the active phase of treatment. Method: In successive cohorts over a 4-year period, a total of 88 college students with well-defined ADHD received CBT in an open clinical trial format that included active treatment and maintenance phases delivered across two consecutive semesters. Results: Immediately following active treatment, participants displayed statistically significant reductions in ADHD symptoms, improvements in executive functioning, and declines in anxiety and depression symptoms. Although grade point average did not improve significantly, there were statistically significant increases in the number of credit hours that participants attempted and earned across active treatment. Improvements in symptom severity, executive functioning, and educational functioning remained stable 5 to 7 months after active treatment concluded. Conclusion: Findings from this study support the use of CBT interventions for college students with ADHD. (J. of Att. Dis. 2020; 24(6) 863-874)
\end{abstract}

Keywords: ADHD | college students | treatment | cognitive-behavioral therapy

Article:

ADHD is a neurodevelopmental disorder characterized by developmentally deviant levels of inattention and/or hyperactivity-impulsivity that typically arise during childhood, persist across the life span, and cause clinically significant impairment across multiple domains of daily functioning (American Psychiatric Association [APA], 2013). In contrast with the large body of published research that has illuminated how ADHD unfolds and affects children and adults 
(Barkley, 2015), relatively less research attention has been focused on these same issues among individuals with ADHD transitioning through the developmental period known as emerging adulthood, from 18 to 25 years of age (Arnett, 2007).

Recently, this emerging adult segment of the ADHD population has received increased research attention, primarily involving individuals attending college. One factor contributing to this postsecondary emphasis is the dramatic increase in the numbers of young adults with ADHD pursuing college degrees over the past decade (Eagan et al., 2014; Weyandt \& DuPaul, 2012; Wolf, Simkowitz, \& Carlson, 2009). Given that college students with ADHD achieved a level of success during high school that made postsecondary admission possible, one might reasonably expect that they would continue to experience educational success during college. Contrary to this expectation, research has shown that, relative to their peers, college students with ADHD display significant academic deficits, including lower end-of-semester grade point averages (GPAs), lower levels of performance on weekly assignments and exams, and less effective study strategies (Advokat, Lane, \& Lou, 2011; Gormley, DuPaul, Weyandt, \& Anastopoulos, 2019; Reaser, Prevatt, Petscher, \& Proctor, 2007; Weyandt et al., 2013). Students with ADHD also experience greater difficulties in their general adjustment to college and are at significantly increased risk for displaying comorbid psychiatric disorders, particularly depression and anxiety (Anastopoulos et al., 2018; Blase et al., 2009; Heiligenstein \& Keeling, 1995). Together, such factors may help to explain why college students with ADHD are more likely to be placed on academic probation, to take longer to complete their degrees, and in far too many cases, to drop out of college (Barkley, Murphy, \& Fischer, 2008; Hechtman, 2017).

Conceptually, it has been suggested that such difficulties are set in motion by a "perfect storm" of life circumstances that converge during the transition from high school into college (Anastopoulos \& King, 2015). Prior to college, many supports may be in place (e.g., parental monitoring, 504 accommodations) to help manage the deficits in self regulation (Barkley, 2015) that a student with ADHD might display. During the transition into college, demands for self regulation dramatically increase, not only with respect to educational matters but also in terms of various personal and social responsibilities. This developmental transition is normative and often the reason why many first-year students, whether they have ADHD or not, experience trouble adjusting to college. For students with ADHD, this same developmental challenge is magnified due to their inherent deficit in self-regulation (Fleming \& McMahon, 2012) and the fact that most, if not all, external supports have been removed (Meaux, Green, \& Broussard, 2009).

To reduce their risk of negative outcomes, it is critically important for college students with ADHD to have ready access to treatment. On many college campuses, disability service offices are the primary mechanism by which students with ADHD receive assistance, most often in the form of extended time on tests and various other accommodations (Wolf et al., 2009). Unfortunately, many college students choose not to use such services (Fleming \& McMahon, 2012). Of additional concern is that accommodations, when used alone, appear to produce minimal long-term benefits (e.g., Lewandowski, Gathje, Lovett, \& Gordon, 2013; Miller, Lewandowski, \& Antshel, 2015) and do not address co-occurring difficulties, such as executive functioning deficits (Antshel, Hier, \& Barkley, 2014) and psychological distress (Weyandt et al., 2013).

Although stimulant medication is a well-established treatment for children and adults with ADHD (Barkley, 2015), its use with college students has thus far been understudied. In the only well-controlled stimulant medication trial focused specifically on college students (DuPaul 
et al., 2012), Lisdexamfetamine dimesylate successfully reduced ADHD symptoms and improved executive functioning. Despite the promising nature of these results, additional medication trials are needed to address not only efficacy issues but also safety concerns, including the risk of misuse, abuse, and diversion on college campuses (Rabiner et al., 2009).

A limited, but increasing, number of studies has examined the impact of psychosocial interventions for college students with ADHD (see He \& Antshel, 2016, for a review). Initial research efforts emphasized a coaching approach, addressing goal setting, organization, and time management (Prevatt \& Yelland, 2015; Swartz, Prevatt, \& Proctor, 2005). More recent investigations have examined the impact of treatment from a diverse array of therapeutic perspectives, including cognitive-behavioral therapy (CBT; Anastopoulos \& King, 2015; Eddy, Canu, Broman-Fulks, \& Michael, 2015; LaCount, Hartung, Shelton, Clapp, \& Clapp, 2015), dialectical behavior therapy (DBT, Fleming, McMahon, Moran, Peterson, \& Dreessen, 2015), self-monitoring (Scheithauer \& Kelley, 2014), and organization, time management, and planning (OTMP) skills training (LaCount, Hartung, Shelton, \& Stevens, 2015).

Findings from these initial investigations have revealed significant improvements in primary ADHD symptoms, most often involving inattention (Anastopoulos \& King, 2015; Eddy et al., 2015; Fleming et al., 2015; LaCount, Hartung, Shelton, Clapp, \& Clapp, 2015). Less often, improvements in self-reported executive functioning have been observed (Anastopoulos \& King, 2015; Fleming et al., 2015). Among the small number of investigations examining comorbid features, results have been mixed, with a statistical trend revealing modest improvements in depression and anxiety symptoms in one study (Anastopoulos \& King, 2015) but no changes in these same emotional features in another (Fleming et al., 2015). Although not routinely assessed, improvements in educational functioning have been reported, including gains in self-reported learning strategies (LaCount, Hartung, Shelton, \& Stevens, 2015; Prevatt \& Yelland, 2015) and increased use of disability services and other campus resources (Anastopoulos \& King, 2015). Corresponding changes in GPA, however, have thus far not been reliably demonstrated (Anastopoulos \& King, 2015; Fleming et al., 2015).

Taken together, results from this emerging literature offer much promise for the role that psychosocial interventions may ultimately play in the overall clinical management of college students with ADHD. At the same time, however, it is necessary to acknowledge that findings have been inconsistent across extant studies, which limits conclusions about efficacy. Because programmatic research in this area has been lacking, many of these inconsistent findings are likely attributable to methodological and conceptual differences across studies (He \& Antshel, 2016). This includes, for example, cross-study differences in the rigor used to identify ADHD and the degree to which comorbid psychiatric conditions were addressed. Additional crossstudy differences are evident with respect to the conceptual underpinnings of treatment (e.g., CBT, DBT, coaching, OTMP), the number of treatment sessions offered (i.e., three to 10 sessions), and the duration of treatment (i.e., 1-3 months). Moreover, only one study to date has included a follow-up outcome assessment (Fleming et al., 2015). In that study, only self-reported improvements in inattention and executive functioning remained stable 3 months after active treatment.

Given the chronicity of ADHD (Barkley, 2015), it is indeed surprising that so little research attention has been directed to the temporal stability of improvements in functioning after active treatment is completed. Equally surprising is the fact that most of the currently available psychosocial treatment programs for college students with ADHD have been short term 
in nature, which runs counter to the prevailing view that treatment of ADHD must be sustained over longer periods of time to have lasting impact (Smith, Barkley, \& Shapiro, 2006).

To shed new light on these issues, this article summarizes findings from a recently completed open clinical trial study examining the cognitive-behavioral treatment program known as ACCESS - Accessing Campus Connections and Empowering Student Success - which includes an active treatment component and a maintenance phase delivered across two consecutive semesters. In an earlier publication (Anastopoulos \& King, 2015), preliminary data from the ongoing pilot development of ACCESS were reported for a subset of participants who had completed the active phase of this intervention, but not its maintenance phase. In the current study, we report findings addressing the complete treatment program, encompassing both the active and maintenance phases of ACCESS spanning a full academic year. The availability of a larger sample that completed the full two-semester sequence of ACCESS allows for a more thorough assessment of the extent to which improvements persist beyond active treatment. The following were hypothesized:

Hypothesis 1: There would be significant improvements in ADHD symptoms, executive functioning, comorbid depression and anxiety, and educational functioning following active treatment.

Hypothesis 2: These improvements would remain stable through the maintenance phase.

\section{Method}

Participants

Students from a large, public university in the southeastern United States participated in an open clinical trial of ACCESS. A total of 106 students were initially consented into the project and screened for eligibility. Five of these students were deemed ineligible, because they either did not have ADHD or displayed an exclusionary condition. Thirteen eligible students did not begin treatment primarily due to scheduling conflicts with planned group meeting times. Thus, there were 88 participants in the final sample, including 52 females and 36 males, ranging in age from 17 to 27 years $(\mathrm{M}=20.2$ years $)$ and representing a cross section of postsecondary education levels (i.e., 38\% first-year students, $24 \%$ sophomores, $21 \%$ juniors, $16 \%$ seniors, $2 \%$ post baccalaureate students). Twelve percent of the participants reported having Hispanic/Latino backgrounds; 64\% identified as Caucasian, 18\% as African American, and 6\% multiracial.

A multimethod, multi-informant assessment was used to determine ADHD and comorbidity status. All participants met Diagnostic and Statistical Manual of Mental Disorders (4th ed; DSM-IV; APA, 1994) criteria for ADHD, as determined by (a) participant responses to a semistructured ADHD interview indicating six or more symptoms of inattention and/or hyperactivity-impulsivity, and all other DSM-IV criteria being met; (b) clear evidence of developmental deviance of ADHD symptoms, defined as at or above the 90th percentile on ADHD indices derived from self-report rating scales; and (c) parent or self-report ratings of clinically significant levels of inattention and/or hyperactivity-impulsivity during childhood. Of the 88 participants who met the study's eligibility criteria, $48 \%$ were diagnosed with an ADHD combined subtype, 48\% displayed a predominantly inattentive (IN) ADHD subtype, and 4\% were given a diagnosis of ADHD not otherwise specified, generally due to an age of onset 
beyond age 7 but by early adolescence.

Comorbidity status was determined from participant responses to a structured clinical interview. To increase the generalizability of the findings, participants with many different types of co-occurring diagnoses (e.g., major depressive disorder, generalized anxiety disorder) were allowed into the study. Because comorbid bipolar disorder and Asperger's disorder require a level of treatment beyond the scope of ACCESS, participants with these conditions were deemed ineligible. Based on their structured interview responses, most participants (56\%) met DSM-IV criteria for at least one currently active comorbid diagnosis; $29 \%$ reported having two or more comorbid conditions. Anxiety disorders were the most frequently encountered comorbid condition (44\%), followed by current major depressive disorders and dysthymic disorders (31\%).

For clinical and ethical reasons, students could participate in ACCESS regardless of whether they were receiving other treatment. During their time in college prior to the study, $52.4 \%$ of the participants had taken medication for ADHD; $34.1 \%$ had received psychotherapy.

\section{Treatment Program}

Development of ACCESS (Anastopoulos \& King, 2015) was influenced by existing CBT programs for adults with ADHD (Safren, Perlman, Sprich, \& Ott, 2005; Solanto, 2011), tailored to the developmental needs of emerging adults in college. ACCESS was refined through an iterative process over 4 years. Throughout the study, ACCESS included an active treatment component, followed by a semester long maintenance phase during which treatment was tapered. During active treatment, participants received six to 10 weekly 90 -min CBT group sessions. A closed format was used for all CBT groups, which varied in size but were limited to no more than eight participants per group. Concurrent with the CBT group timeline, participants received weekly 30-min individual mentoring sessions. During the maintenance phase, participants received one to two booster CBT group sessions and four to six mentoring sessions.

During active treatment, the goals of the CBT group portion of ACCESS are to (a) increase knowledge of ADHD and awareness of campus resources; (b) improve use of planning, organization, time management, and other behavioral skills affecting executive functioning; and (c) teach cognitive therapy strategies targeting maladaptive thinking patterns related to academic impairment, social impairment, risk of secondary emotional problems, and treatment adherence. In contrast with existing CBT programs for adults (Safren et al., 2005; Solanto, 2011), all three ACCESS goals are addressed simultaneously, rather than successively, within each of the group sessions (see Table 1). The rationale for doing so was to maximize participant interest and engagement throughout the entire group session. The inclusion of a substantially more intensive ADHD psychoeducation module is another feature of ACCESS that differentiates it from the adult CBT programs. Yet another important distinction is the fact that ACCESS incorporates mentoring, an approach commonly used on many college campuses to address a wide variety of student needs. Within ACCESS, the purpose of individual mentoring is to (a) reinforce what the student learned in the CBT groups, (b) help the student make connections with campus resource units as needed (e.g., disability services, student counseling center), and (c) assist the student in establishing realistic personal goals and monitoring progress.

During the maintenance phase, CBT group sessions are less structured and tailored to the individual needs of participants (e.g., troubleshooting difficulties implementing behavioral strategies, fine tuning use of cognitive therapy strategies). Likewise, mentoring sessions are 
fewer in number and more flexible, guided primarily by participant needs and preferences.

Table 1. Outline of Topics Covered in the CBT Group Sessions During Eight-Session Active Phase of Treatment.

\begin{tabular}{|c|c|c|c|c|c|c|c|c|}
\hline & 1 & 2 & 3 & 4 & 5 & 6 & 7 & 8 \\
\hline $\begin{array}{l}\text { ADHD } \\
\text { Knowledge }\end{array}$ & $\begin{array}{l}\text { Introduction to } \\
\text { ACCESS } \\
\text { What is ADHD? }\end{array}$ & $\begin{array}{l}\text { What causes } \\
\text { ADHD? }\end{array}$ & $\begin{array}{l}\text { Assessment of } \\
\text { ADHD }\end{array}$ & $\begin{array}{l}\text { How does ADHD } \\
\text { affect school? } \\
\text { Does ADHD only } \\
\text { affect school? }\end{array}$ & $\begin{array}{l}\text { Depression, } \\
\text { anxiety, and other } \\
\text { things that may } \\
\text { go with ADHD } \\
\text { Sex, drugs, and } \\
\text { ADHD }\end{array}$ & $\begin{array}{l}\text { What } \\
\text { medications } \\
\text { are used to } \\
\text { treat ADHD? }\end{array}$ & $\begin{array}{l}\text { Is medication } \\
\text { the only } \\
\text { way to treat } \\
\text { ADHD? }\end{array}$ & $\begin{array}{l}\text { A look into the } \\
\text { future }\end{array}$ \\
\hline $\begin{array}{l}\text { Behavioral } \\
\text { Strategies }\end{array}$ & $\begin{array}{l}\text { Accessing } \\
\text { campus } \\
\text { resources }\end{array}$ & $\begin{array}{l}\text { Choosing } \\
\text { tools: } \\
\text { using a } \\
\text { planner and } \\
\text { notebook }\end{array}$ & $\begin{array}{l}\text { Getting } \\
\text { organized }\end{array}$ & $\begin{array}{l}\text { Getting the most } \\
\text { from classes }\end{array}$ & Studying effectively & $\begin{array}{l}\text { Taking exams } \\
\text { Managing papers } \\
\text { and long term } \\
\text { projects }\end{array}$ & $\begin{array}{l}\text { Healthy } \\
\text { lifestyle } \\
\text { Handling } \\
\text { relationships }\end{array}$ & $\begin{array}{l}\text { Setting long- } \\
\text { term goals } \\
\text { Maintaining your } \\
\text { skills }\end{array}$ \\
\hline $\begin{array}{l}\text { Cognitive } \\
\text { Therapy }\end{array}$ & $\begin{array}{l}\text { What is } \\
\text { cognitive } \\
\text { therapy? }\end{array}$ & $\begin{array}{l}\text { Recognizing } \\
\text { maladaptive } \\
\text { thinking }\end{array}$ & $\begin{array}{l}\text { Replacing } \\
\text { maladaptive } \\
\text { thinking with } \\
\text { adaptive } \\
\text { thinking }\end{array}$ & $\begin{array}{l}\text { How can adaptive } \\
\text { thinking help me } \\
\text { manage ADHD } \\
\text { and improve my } \\
\text { school work? }\end{array}$ & $\begin{array}{l}\text { Dealing with } \\
\text { emotions and } \\
\text { resisting harmful } \\
\text { temptations }\end{array}$ & $\begin{array}{l}\text { Sticking with } \\
\text { treatment }\end{array}$ & $\begin{array}{l}\text { Improving } \\
\text { relations } \\
\text { with friends } \\
\text { and family }\end{array}$ & $\begin{array}{l}\text { An adaptive } \\
\text { thinking look } \\
\text { into the future } \\
\text { Relapse } \\
\text { prevention }\end{array}$ \\
\hline
\end{tabular}

Note. $\mathrm{CBT}=$ cognitive-behavioral therapy; ACCESS = Accessing Campus Connections and Empowering Student Success.

Throughout the study, all CBT group sessions were delivered by a licensed doctoral-level psychologist (K.A.K.) with extensive experience in the assessment and treatment of individuals with ADHD. Mentoring was provided by graduate students in doctoral-level psychology training programs, a postdoctoral fellow in clinical psychology, and licensed doctoral-level psychologists, all of whom received extensive training prior to providing treatment to participants. Treatment fidelity was further enhanced through the development of a treatment manual containing detailed session-by-session outlines to guide the CBT group leaders and mentors in their delivery of ACCESS. Treatment adherence checks were performed via reviews of randomly selected audio recordings of $20 \%$ of the CBT group sessions. Overall, adherence was excellent, with all reviewed sessions meeting the criterion that at least $85 \%$ of planned session content was covered.

Diagnostic Measures

ADHD Rating Scale-IV (ADHD RS-IV). The ADHD RS-IV is an 18-item questionnaire that possesses excellent reliability and validity and has been used widely in research and practice (DuPaul, Power, Anastopoulos, \& Reid, 1998). Inattentive (IN) and hyperactive-impulsive (HI) symptoms are rated from 0 (not at all present) to 3 (very often present). Items with scores of 2 (often) or 3 (very often) are summed to yield frequency counts ranging from 0 to 9 for each symptom cluster. In addition to addressing current symptoms, the self-report and parent-report versions of the ADHD RS-IV used in this study were modified to include a column for rating each symptom during childhood. Together, these self-report/parent-report ratings were used to assess the frequency of ADHD symptoms as part of the process of determining ADHD status.

Conners’ Adult ADHD Rating Scale, Self-Report, Long Version (CAARS-S:L). The 
CAARS-S:L is a psychometrically sound rating scale for evaluating ADHD in adults (Conners, Erhardt, \& Sparrow, 2006). In this study, the DSM-IV IN and HI subscales were used to assess the developmental deviance of ADHD symptoms.

Semistructured Interview for Adult ADHD. The Semistructured Interview for Adult ADHD was developed specifically for this study because it allowed for a more thorough assessment of ADHD-specific impairment. The 18 symptom descriptions for ADHD are initially presented, after which questioning is directed to the other DSM-IV criteria addressing impairment, duration, age of onset, and exclusionary conditions. Preliminary analyses of data from an ongoing longitudinal study indicate that this interview possesses adequate internal consistency (.84-.90) and is highly correlated with CAARS-S:L symptom dimensions (.78-.84).

Structured Clinical Interview for DSM Disorders (SCID-I). The SCID-I is a psychometrically sound, clinician-administered structured interview that assesses a wide range of DSM-IV psychiatric disorders (First, Spitzer, Gibbon, \& Williams, 1996). The mood and anxiety disorders modules from the SCID-I were routinely administered to determine whether these commonly occurring comorbid conditions were present. Additional SCID-I modules were given when clinically indicated to address other comorbid concerns and/or exclusionary conditions.

Outcome Measures for ADHD, Executive Functioning, and Comorbid Symptoms

CAARS-S:L. In addition to assessing developmental deviance, the DSM-IV IN and HI subscales were used to assess treatment-related changes in ADHD symptoms (Conners et al., 2006).

Behavior Rating Inventory of Executive Function-Adult Version (BRIEF-A). The BRIEF-A is a commonly used self-report measure of executive functioning (EF) among adults (Gioia, Isquith, Guy, \& Kenworthy, 2000). In addition to subscales, the BRIEF-A yields composite scores, including the behavior regulation index (BRI) and the metacognition index (MI), which served as outcome variables in this study. Higher scores on these composites indicate poorer EF.

Beck Depression Inventory-Second Edition (BDI-II). The BDIII is a 21-item self-report questionnaire that is widely used in research and practice as a measure of depression (Beck, Steer, \& Brown, 1996). Items are rated on a 0 to 3 frequency scale and then summed to yield an overall depression score, which served as a measure of changes in depressed mood in this study.

Beck Anxiety Inventory (BAI). The BAI is a psychometrically sound self-report measure containing 21 items scored on a 0 to 3 frequency scale (Beck \& Steer, 1993). Scores for each item are summed to yield an overall anxiety score, which was used as an outcome measure in this study.

Archival data. With participant consent, the university registrar provided educational record data from the semester preceding ACCESS, the semester in which active treatment was delivered, and the maintenance phase semester. GPA, the number of credit hours attempted, and the number of credit hours earned from each semester were used as outcome indices. Because $38 \%$ of the participants were in their first semester of college, their pretreatment educational data were not 
available, thus reducing the sample size for these analyses.

Other educational data. Given the likelihood that large numbers of students in their first semester of college would be involved in future ACCESS studies, consideration was given to pilot testing other ways in which educational functioning could be measured to ensure the availability of pretreatment data. Thus, for the final two ACCESS cohorts in the fourth year of the study, the Learning and Study Strategies Inventory, Second Edition (LASSI; Weinstein \& Palmer, 2002) was included as an educational outcome measure on an exploratory basis. The LASSI is a psychometrically sound self report rating of students' awareness and use of learning and study strategies. Each of the LASSI's 80 items are rated on a 5-point Likert-type scale $(1=$ not at all typical of me, 5 = very much typical of me) and summed to yield 10 subscales that cluster under three factors - comprehension monitoring strategies, affective strategies, and goal strategies. In this study, the three subscales from the comprehension monitoring strategies factor (i.e., information processing, self-testing, study aids) and two subscales from the affective factor (i.e., attitude, motivation) were used to assess self-reported changes in educational functioning following active treatment. These subscales were selected based upon their relevance to the goals of ACCESS and because they overlapped minimally with other measures used in the study.

\section{Connections to Campus Resources}

One of the goals of mentoring is to assess a participant's need for additional treatment and support services and to help participants connect with campus resources as needed. This was assessed via a service utilization questionnaire prior to and following active treatment, as well as at the end of the maintenance phase. In this study, participant use of ADHD medications, disability accommodations, psychotherapy, and campus tutoring were the outcomes of interest.

Hypothesized Mechanisms of Clinical Change

Knowledge of ADHD, behavioral strategies, and adaptive thinking skills are conceptualized as the mechanisms of clinical change within ACCESS. Because we were not aware of any existing measures of these clinical change mechanisms, we assessed these constructs on an exploratory basis using the following study-specific instruments.

Test of ADHD Knowledge (TOAK). The TOAK is a 50-item test that measures general knowledge of ADHD, including questions about etiology, prevalence, developmental course, comorbidity, impairments, and evidence-based treatments. For each item, participants are asked to respond to statements about ADHD with "agree," "disagree," or "not sure." Correctly endorsed "agree" and "disagree" items are summed to yield a total score, with higher scores indicating greater knowledge of ADHD. Preliminary findings from an ongoing longitudinal study suggest adequate internal consistency $(r=.84)$ and 1 -year test-retest reliability $(r=.84)$.

Strategies for Success (SFS). The SFS contains 30 items describing time management, organization, and other behavioral strategies for educational success. Participants rate each item on a 5-point scale based on frequency of use. Items are summed to yield a total score, with higher scores indicating more frequent behavioral strategy use. Preliminary findings from an ongoing treatment study suggest that the SFS possesses excellent internal consistency $(\mathrm{r}=.88)$. 
ADHD Cognitions Scale (ACS). The ACS is a 20-item questionnaire that assesses self-reported frequency of ADHDrelated cognitions (e.g., "I need it now"). Each item is rated on a 5-point scale, and ratings for all 20 items are summed to create a total ACS score, with higher scores reflecting more frequent engagement in maladaptive thinking patterns. Preliminary findings from an ongoing longitudinal study suggest that the ACS is internally consistent $(r=.87)$ and demonstrates discriminant validity, such that students with ADHD report significantly more maladaptive cognitions than do controls $(\mathrm{p}<.05)$.

Procedure

Students were recruited from multiple sources, including various campus units (e.g., ADHD clinic, disability services), first-year summer orientation sessions, and campus fliers. Potential participants who had not been evaluated in the ADHD clinic underwent an initial two-stage screening process to determine eligibility. If they reported four or more IN or HI symptoms occurring often or very often on the ADHD RS-IV and had CAARS-S:L scores suggesting developmental deviance, they proceeded to the second stage, during which the Semistructured Interview and the SCID-I were administered to determine ADHD and comorbidity status. Students who had recently been evaluated in the ADHD clinic and deemed eligible for the study were not required to undergo a reevaluation, as the same measures were used in all cases.

Recruitment was ongoing and the ACCESS program was delivered to successive cohorts of participants across consecutive semesters from 2011 through 2015. Thus, some participants started ACCESS in the fall and finished in the spring, whereas the reverse was true for others. Treatment outcome data were collected on three occasions: within 2 weeks prior to beginning active treatment, immediately after active treatment, and in the final 2 to 3 weeks of the maintenance phase semester. All study procedures were approved annually by the university's institutional review board. Participants received monetary compensation for completing outcome measures, along with a written screening evaluation summary, which could be used as documentation for various services on campus (e.g., disability service accommodations).

\section{Results}

Attrition

During active treatment, 80 of the 88 participants completed at least $80 \%$ of the CBT group program, and 73 completed at least $80 \%$ of their mentoring sessions. For a variety of reasons (e.g., leaving the university), 23 of the 88 students were not eligible to participate in the maintenance phase. Of the remaining 65 participants, 41 completed at least one CBT group booster session and 51 participated in mentoring. Regardless of the degree of involvement in treatment, efforts were made to collect postactive and postmaintenance data from all participants.

\section{Data Analytic Approach}

Latent change score (LCS) analyses were used to examine changes in ADHD symptoms, executive functioning, and symptoms of depression and anxiety. LCS is a procedure using latent 
variables that specifies baseline (intercept) and change (e.g., preactive to postactive, preactive to postmaintenance) latent variables that capture baseline scores for the sample and change across time points. This analysis is comparable with conducting simple difference scores; however, by including reliability estimates and by creating latent variables, associations are less likely biased due to attenuation associated with measurement error. In addition, the use of latent variables in a structural equation modeling context allows for the application of full information maximum likelihood (FIML), which includes all available data for the final estimates and which is the least biased method of handling missing data. LCS was also used in the exploratory examination of hypothesized mechanisms of clinical change - namely, ADHD knowledge, behavioral strategies, and adaptive thinking. LCS was not, however, used for the analyses of the educational record and LASSI data, due to the substantially reduced size of the sample. For this purpose, repeated-measures ANOVAs were used instead. For the examination of changes in participant use of campus resources, Cochran's Q tests for related samples were performed.

Table 2. Latent Change Score Means and Effect Sizes for ADHD, Executive Functioning, Depression, and Anxiety $(\mathrm{N}=88)$

\begin{tabular}{|c|c|c|c|}
\hline Variable & Mean latent difference & $95 \% \mathrm{Cl}$ & Standardized mean difference \\
\hline \multicolumn{4}{|l|}{ IN symptoms } \\
\hline Active treatment & $-4.43^{* \mathrm{~kat}}$ & {$[-5.65,-3.20]$} & -0.78 \\
\hline Maintenance phase & $-4.56^{\text {*eoper }}$ & {$[-6.08,-3.29]$} & -0.83 \\
\hline \multicolumn{4}{|l|}{ HI symptoms } \\
\hline Active treatment & $-1.82^{\text {wew }}$ & {$[-2.92,-0.84]$} & -0.38 \\
\hline Maintenance phase & $-2.12^{\text {wak }}$ & {$[-3.48,-1.02]$} & -0.43 \\
\hline \multicolumn{4}{|l|}{ Behavioral regulation } \\
\hline Active treatment & $-6.15^{* \infty \mathrm{k} k}$ & {$[-8.19,-4.05]$} & -0.64 \\
\hline Maintenance phase & -4.49 com & {$[-6.97,-2.71]$} & -0.53 \\
\hline \multicolumn{4}{|l|}{ Metacognition } \\
\hline Active treatment & $-10.55^{\text {wow }}$ & {$[-13.79,-7.01]$} & -0.66 \\
\hline Maintenance phase & $-7.63^{\text {topok }}$ & {$[-11.91,-4.85]$} & -0.58 \\
\hline \multicolumn{4}{|l|}{ Anxiety symptoms } \\
\hline Active treatment & $-3.74^{\text {towk }}$ & {$[-5.69,-1.87]$} & -0.42 \\
\hline Maintenance phase & $-5.42^{\text {tewk }}$ & {$[-7.86,-3.35]$} & -0.58 \\
\hline \multicolumn{4}{|l|}{ Depression symptoms } \\
\hline Active treatment & $-2.76^{\text {ick }}$ & {$[-4.58,-1.06]$} & -0.34 \\
\hline Maintenance phase & $-3.20^{k 0 k}$ & {$[-6.05,-1.09]$} & -0.35 \\
\hline
\end{tabular}

Note. $\mathrm{CI}=$ confidence interval; $\mathrm{IN}=$ inattention; $\mathrm{HI}=$ hyperactive-impulsive.

${ }^{\text {a }}$ Standardized change scores may be interpreted as effect sizes (d).

$* * \mathrm{p}<.01 . * * * \mathrm{p}<.001$.

Changes in ADHD, Executive Functioning, and Comorbid Symptoms

Statistically significant average changes were evident in multiple domains of functioning from preactive to postactive treatment, which were maintained from preactive treatment through the postmaintenance phase (Table 2). ADHD IN and HI symptoms improved significantly across both phases of treatment, with standardized mean differences in these two outcomes suggesting that change effect sizes were large for IN and small to medium for HI. In terms of executive functioning, there were statistically significant improvements in behavioral regulation and metacognition scores across both ACCESS phases, representing medium effect sizes. Anxiety 
and depressive symptoms also declined significantly throughout treatment, representing medium and small effect sizes for anxiety and depression, respectively.

\section{Changes in Educational Functioning}

As shown in Table 3, GPA improved across treatment but did not reach a level of statistical significance, $\mathrm{F}(2)=0.91, \mathrm{p}=.41$. In contrast, there were statistically significant improvements in both the number of semester credit hours that participants attempted, $F(2)=5.78, p=.005$, and the number of semester credit hours earned, $\mathrm{F}(2)=3.64, \mathrm{p}=.031$. For both credit hours attempted and earned, significant improvements were evident not only across the preactive to postactive periods but also across the preactive to postmaintenance phases. Examination of the three subscales from the LASSI comprehension monitoring factor revealed statistically significant preactive to postactive increases in information processing, $\mathrm{F}(2)=7.18, \mathrm{p}=.014$; self-testing, $F(2)=5.21, p=.032$; and study aids, $F(2)=15.79, p=.001$. For the two LASSI affective factor subscales, a similar pattern of improvement was found for the motivation subscale, $\mathrm{F}(2)=9.61, \mathrm{p}=.005$, but not for the attitude subscale, $\mathrm{F}(2)=0.94, \mathrm{p}=.344$.

\section{Changes in Use of Campus Resources}

The percentages of participants registered with the disability office (see Table 4 ) increased significantly from $41.5 \%$ to $71.1 \%$ following active treatment, and remained high $(67.3 \%)$ at the end of the maintenance phase $(\mathrm{p}<.001)$. This increase in registration was accompanied by greater use of accommodations, which increased significantly from $24.4 \%$ to $63.2 \%$ from preactive to postactive treatment and remained stable after the maintenance phase, $60.0 \%(\mathrm{p}<$ .001). Participant use of ADHD medication also increased significantly from $52.4 \%$ to $64.5 \%$ to $72.7 \%$ across the preactive, postactive, and postmaintenance phases, respectively $(p=.041)$. Although participant use of campus-based psychotherapy and tutoring services declined slightly across both phases of treatment, neither of these changes was significant.

\section{Changes in Hypothesized Mechanisms of Clinical Change}

Consistent with our conceptualization of ACCESS, significant improvements were found for the hypothesized mechanisms of clinical change (see Table 5). From preactive to postactive treatment, there were statistically significant average increases in both ADHD knowledge and use of behavioral strategies, along with a statistically significant average decline in maladaptive thinking. These improvements were also evident from preactive treatment to postmaintenance. Effect sizes across both the active and maintenance phases ranged from large (behavioral strategies and maladaptive thinking) to very large (ADHD knowledge). 
Table 3. Summary of Repeated-Measures ANOVA Results for Educational Outcomes.

\begin{tabular}{|c|c|c|c|c|c|}
\hline Variable & $\begin{array}{l}\text { Preactive } \\
M(S D)\end{array}$ & $\begin{array}{l}\text { Postactive } \\
M(S D)\end{array}$ & $\begin{array}{c}\text { Postmaintenance } \\
\text { M (SD) }\end{array}$ & $F$ & $p$ \\
\hline \multicolumn{6}{|l|}{ Archival data ${ }^{2}$} \\
\hline Grade point average & $2.58(0.93)$ & $2.75(0.89)$ & $2.77(0.83)$ & 0.91 & ns \\
\hline Credit hours attempted & $12.42(3.04)$ & $13.87(2.52)^{b}$ & $13.53(2.91)^{c}$ & 5.78 & .005 \\
\hline Credit hours earned & $10.97(4.06)$ & $12.74(3.65)^{b}$ & $12.39(3.58)^{c}$ & 3.64 & .035 \\
\hline \multicolumn{6}{|l|}{ LASSI subscales ${ }^{d}$} \\
\hline Information processing & $25.17(6.42)$ & $27.74(6.70)$ & - & 7.18 & .014 \\
\hline Self-testing & $17.13(4.87)$ & $19.48(5.47)$ & - & 5.21 & .032 \\
\hline Study aids & $20.26(5.47)$ & $23.00(5.70)$ & - & 15.79 & .001 \\
\hline Attitude & $28.13(4.94)$ & $29.26(5.78)$ & - & 0.94 & ns \\
\hline Motivation & $24.48(5.84)$ & $28.17(6.72)$ & - & 9.61 & .005 \\
\hline
\end{tabular}

Note. LASSI = Learning and Study Strategies Inventory.

${ }^{a} \mathrm{n}=38$ for analyses of archival data.

${ }^{\mathrm{b}}$ Significant preactive to postactive difference.

${ }^{c}$ Significant preactive to postmaintenance difference.

${ }^{\mathrm{d}} \mathrm{n}=23$ for analyses of LASSI subscales.

Table 4. Summary of Changes in Participants' Use of Campus Services.

\begin{tabular}{lccc}
\hline Variable & $\begin{array}{c}\text { Preactive } \\
\%\end{array}$ & $\begin{array}{c}\text { Postactive } \\
\%\end{array}$ & $\begin{array}{c}\text { Postmaintenance } \\
\%\end{array}$ \\
\hline Registered with disability services $^{2}$ & 41.5 & 71.1 & 67.3 \\
Using disability accommodations $^{2}$ & 24.4 & 63.2 & 60.0 \\
Taking ADHD medication $^{b}$ & 52.4 & 64.5 & 72.7 \\
Receiving psychotherapy $_{\text {Receiving tutoring }}$ & 34.1 & 22.4 & 23.6 \\
\hline
\end{tabular}

${ }^{a}$ Cochran's $\mathrm{Q}$ test for related samples significant $(\mathrm{p}<.001)$.

${ }^{\mathrm{b}}$ Cochran's $\mathrm{Q}$ test for related samples significant $(\mathrm{p}<.05)$.

\section{Discussion}

The results of this open clinical trial revealed numerous improvements in functioning among college students with ADHD following their participation in a full, two-semester sequence of ACCESS. Upon completion of the active phase, participants displayed statistically significant changes in multiple domains of functioning, including reductions in the overall severity of their ADHD symptoms, encompassing both IN and HI features; improvements in the behavioral regulation and metacognitive components of executive functioning; declines in the overall severity of anxiety and depression symptoms; increases in the number of semester credit hours attempted and earned; and increases in the use of both disability service accommodations and ADHD medications. Of further clinical significance is that the improvements in symptom severity, executive functioning, and educational functioning persisted throughout the maintenance phase of ACCESS, 5 to 7 months after active treatment.

Although these results are generally in line with previous findings (Fleming et al., 2015; LaCount, Hartung, Shelton, Clapp, \& Clapp, 2015), the improvements in HI symptoms and executive functioning, along with the reductions in anxiety and depression, are relatively unique 
to this investigation as they have not been consistently found in prior research. Our examination of educational outcome went beyond the traditional metric of GPA and revealed a significant increase in the number of semester credit hours that ACCESS participants attempted and earned. The importance of this finding can best be understood in terms of the impact that this may have on a student's progress toward graduation, which is an ongoing concern in many colleges and universities. Because ACCESS is not viewed to be a stand-alone intervention, one of its goals is to connect participants with campus resources that can provide whatever additional assistance they might need. To this end, our results showed significant increases in the percentages of students registering for disability services, using recommended disability accommodations, and initiating pharmacotherapy services. Our exploratory examination of the conceptual underpinnings of ACCESS also revealed significant increases in ADHD knowledge and behavioral strategies, along with reductions in maladaptive thinking. Although encouraging, it is important to keep in mind that these results emanated from an open clinical trial and, therefore, cannot be used to identify clinical change mechanisms with any degree of certainty. Nonetheless, these results are consistent with the possibility that knowledge of ADHD, behavioral strategies, and adaptive thinking skills may be mechanisms of clinical change within ACCESS.

Also emerging from this study is the important finding that observed improvements in functioning remain stable 5 to 7 months beyond active treatment. In the only other study to address temporal stability, self-reported improvements in inattention and executive functioning remained stable 3 months after active treatment (Fleming et al., 2015). The current results add to this limited literature by demonstrating that a broad array of improvements can be maintained over a longer period of time following active treatment. Whether this is due to the impact of active treatment alone, versus active treatment in combination with a maintenance phase, cannot be determined from the open clinical trial format used in this study. Regardless of the reason, the current findings raise the possibility that ACCESS may provide students with the knowledge and skills necessary for dealing more effectively with the chronic impact of their ADHD.

Although promising, findings from this study must be tempered by a consideration of various methodological limitations. For example, because this was an open clinical trial in which there was no control or comparison group, it is not possible to determine whether observed improvements may have been due to nonspecific therapist variables, repeat testing, or other factors beyond the scope of the treatment protocol. Thus, for efficacy to be established, ACCESS will need to be tested further in a randomized controlled trial (RCT), which would also allow for a more thorough examination of the association between functional outcomes and hypothesized mechanisms of clinical change. Consistent with a phased intervention development approach (Rounsaville, Carroll, \& Onken, 2001), we are currently conducting a large-scale, multisite RCT investigation that builds upon these open clinical trial findings. Assuming efficacy is established, it will then be necessary to address the effectiveness of ACCESS more systematically. In the current study, licensed doctoral-level psychologists and advanced doctoral-level graduate students with extensive experience in working with ADHD populations delivered ACCESS to participants. Remaining unclear is the degree to which ACCESS can be successful when delivered by professional staff lacking this same level of ADHD expertise, as would be the case on most college campuses.

The fact that participants could receive stimulant medication during ACCESS is another factor limiting interpretation of the findings. Because medication status was not monitored precisely throughout treatment, it was not possible to examine the potential contribution of 
stimulant medication to reported outcomes. For certain outcomes, such as the observed improvements in primary ADHD symptoms and executive functioning, not controlling for stimulant medication status makes it especially difficult to ascertain the degree to which ACCESS, either alone or in combination with medication, contributed to these changes. Making this same determination, however, is less problematic when considering some of the other observed improvements (e.g., increased ADHD knowledge, decreased maladaptive thinking, lower levels of depression and anxiety), which stimulants are not known to influence. To gain a better understanding of ACCESS's unique contribution to outcome, future studies will need to carefully monitor stimulant medication status throughout treatment and routinely include this variable in statistical analyses.

Although the sample used in this investigation is relatively large in comparison with other published studies, an even larger sample of college students with well-defined ADHD would be needed to conduct more refined analyses of various individual differences and other factors that may affect treatment outcome (e.g., holding down a job while attending college, having comorbid anxiety vs. depression, adhering to medication regimens). Finally, because ACCESS delivers its active treatment and maintenance phases across two consecutive semesters, it would be useful for future research to assess outcome 6 to 12 months after the maintenance phase to gain a more complete understanding of the persistence of therapeutic benefits in the absence of ongoing treatment.

Bearing these limitations in mind, the results of this study offer much promise for using ACCESS as a treatment for college students with ADHD. Specifically, the obtained findings suggest that ACCESS has great potential for bringing about significant improvements in multiple domains of functioning, which remain stable over time and which seem to be conceptually related to the program's hypothesized mechanisms of clinical change. Because ACCESS was designed specifically to accommodate the developmental needs of this population of emerging adults with ADHD, it likely can be implemented in many different college and university settings. Of additional significance, participation in ACCESS can serve as a protective factor that increases the likelihood that college students with ADHD can be more successful not only during college but also as they begin their developmental transition into the post college adult world.

\section{Declaration of Conflicting Interests}

The author(s) declared the following potential conflicts of interest with respect to the research, authorship, and/or publication of this article: Dr. Anastopoulos has a financial interest in the ADHD Rating Scale-IV, a modified version of which was used in this study.

\section{Funding}

The author(s) disclosed receipt of the following financial support for the research, authorship, and/or publication of this article: This research was part of the College STAR project, supported by funding from the Oak Foundation, the North Carolina GlaxoSmithKline Foundation, and a consortium of private foundations in Greensboro, NC.

\section{References}


Advokat, C., Lane, S. M., \& Lou, C. (2011). College students with and without ADHD: Comparison of self-report of medication usage, study habits, and academic achievement. Journal of Attention Disorders, 15, 656-666.

American Psychiatric Association. (1994). Diagnostic and statistical manual of mental disorders (4th ed.). Washington, DC: Author.

American Psychiatric Association. (2013). Diagnostic and statistical manual of mental disorders (5th ed.). Arlington, VA: American Psychiatric Publishing.

Anastopoulos, A. D., DuPaul, G. J., Weyandt, L. L., MorrisseyKane, E., Sommer, J. L., Rhoads, L. H., . . . Gudmundsdottir, B. G. (2018). Rates and patterns of comorbidity among firstyear college students with ADHD. Journal of Clinical Child \& Adolescent Psychology, 47(2), 236-247. https://doi.org/10. 1080/15374416.2015.1105137

Anastopoulos, A. D., \& King, K. A. (2015). A cognitive-behavior therapy and mentoring program for college students with ADHD. Cognitive and Behavioral Practice, 22, 141-151. doi:10.1016/j.cbpra.2014.01.002

Antshel, K. M., Hier, B. O., \& Barkley, R. A. (2014). Executive functioning theory and ADHD. In S. Goldstein \& J. A. Naglieri (Eds.), Handbook of executive functioning (pp. 107120). New York, NY: Springer.

Arnett, J. J. (2007). Emerging adulthood: What is it, and what is it good for? Child Development Perspectives, 1, 68-73. Barkley, R. A. (2015). Attention-deficit hyperactivity disorder: A handbook for diagnosis and treatment (4th ed.). New York, NY: Guilford Press.

Barkley, R. A., Murphy, K. R., \& Fischer, M. (2008). Adult ADHD: What the science says. New York, NY: Guilford Press.

Beck, A. T., \& Steer, R. A. (1993). Beck Anxiety Inventory. San Antonio, TX: Psychological Corporation.

Beck, A. T., Steer, R. A., \& Brown, G. K. (1996). Beck Depression Inventory-II. San Antonio, TX: Psychological Corporation.

Blase, S. L., Gilbert, A. N., Anastopoulos, A. D., Costello, E. J., Hoyle, R. H., Swartzwelder, H. S., \& Rabiner, D. L. (2009). Self-reported ADHD and adjustment in college:

Crosssectional and longitudinal findings. Journal of Attention Disorders, 13, 297-309.

Conners, C. K., Erhardt, D., \& Sparrow, E. (2006). Conners' Adult ADHD Rating Scales. North Tonawanda, NY: Multi-Health Systems.

DuPaul, G. J., Power, T. J., Anastopoulos, A. D., \& Reid, R. (1998). Manual for the ADHD Rating Scale-IV. New York, NY: Guilford Press.

DuPaul, G. J., Weyandt, L. L., Rossi, J. S., Vilardo, B. A., O’Dell, S. M., Carson, K. M., . . . Swentosky, A. (2012). Doubleblind, placebo-controlled, crossover study of the efficacy and safety of Lisdexamfetamine Dimesylate in college students with ADHD. Journal of Attention Disorders, 16, 202-220.

Eagan, K., Stolzenberg, E. B., Ramirez, J. J., Aragon, M. C., Suchard, M. R., \& Hurtado, S. (2014). The American freshman: National norms fall 2014. Los Angeles: Higher Education Research Institute, University of California, Los Angeles.

Eddy, L. D., Canu, W. H., Broman-Fulks, J. J., \& Michael, K. D. (2015). Brief cognitive-behavioral therapy for college students with ADHD: A case series report. Cognitive and Behavioral Practice, 22, 127-140.

First, M. B., Spitzer, R. L., Gibbon, M., \& Williams, B. W. (1996). Structured Clinical Interview for DSM-IV Axis I Disorders, Clinician Version (SCID-CV). Washington, DC: 
American Psychiatric Press.

Fleming, A. P., \& McMahon, R. J. (2012). Developmental context and treatment principles for ADHD among college students. Clinical Child and Family Psychology Review, 15, 303-329.

Fleming, A. P., McMahon, R. J., Moran, L. R., Peterson, A. P., \& Dreessen, A. (2015). Pilot randomized controlled trial of dialectical behavior therapy group skills training for ADHD among college students. Journal of Attention Disorders, 19, 260-271.

Gioia, G. A., Isquith, P. K., Guy, S., \& Kenworthy, L. (2000). BRIEF: Behavior Rating Inventory of Executive Function professional manual. Lutz, FL: Psychological Assessment Resources.

Gormley, M. J., DuPaul, G. J., Weyandt, L. L., \& Anastopoulos, A. D. (2019). First-year GPA and academic service use among college students with and without ADHD. Journal of Attention Disorders, 23(14), 1766-1779. https://doi. org/10.1177/1087054715623046

He, J. A., \& Antshel, K. M. (2016). Cognitive behavioral therapy for attention-deficit/hyperactivity disorder (ADHD) in college students: A review of the literature. Cognitive and Behavioral Practice. Advanced online publication. http:// dx.doi.org/10.1016/j.cbpra.2016.03.010.

Hechtman, L. (2017). Attention deficit hyperactivity disorder: Adult outcome and its predictors. New York, NY: Oxford University Press.

Heiligenstein, E., \& Keeling, R. P. (1995). Presentation of unrecognized attention deficit hyperactivity disorder in college students. Journal of American College Health, 43, 226-228.

LaCount, P. A., Hartung, C. M., Shelton, C. R., Clapp, J. D., \& Clapp, T. K. W. (2015). Preliminary evaluation of a combined group and individual treatment for college students with attention-deficit/hyperactivity disorder. Cognitive and Behavioral Practice, 22, 152-160.

LaCount, P. A., Hartung, C. M., Shelton, C. R., \& Stevens, A. E. (2015). Efficacy of an organizational skills intervention for college students with ADHD symptomatology and academic difficulties. Journal of Attention Disorders. https://doi. org/10.1177/1087054715594423

Lewandowski, L., Gathje, R. A., Lovett, B. J., \& Gordon, M. (2013). Test-taking skills in college students with and without ADHD. Journal of Psychoeducational Assessment, 31, 41-52.

Meaux, J. B., Green, A., \& Broussard, L. (2009). ADHD in the college student: A block in the road. Journal of Psychiatric and Mental Health Nursing, 16, 248-256.

Miller, L. A., Lewandowski, L. J., \& Antshel, K. M. (2015). Effects of extended time for college students with and without ADHD. Journal of Attention Disorders, 19, 678-686.

Prevatt, F., \& Yelland, S. (2015). An empirical evaluation of ADHD coaching in college students. Journal of Attention Disorders, 19, 666-677.

Rabiner, D. L., Anastopoulos, A. D., Costello, E. J., Hoyle, R. H., McCabe, S. E., \& Swartzwelder, H. S. (2009). Motives and perceived consequences of nonmedical ADHD medication use by college students: Are students treating themselves for attention problems? Journal of Attention Disorders, 13, 259-270.

Reaser, A., Prevatt, F., Petscher, Y., \& Proctor, B. (2007). The learning and study strategies of college students with ADHD. Psychology in the Schools, 44, 627-638.

Rounsaville, B. J., Carroll, K. M., \& Onken, L. S. (2001). A stage model of behavioral therapies 
research: Getting started and moving on from stage I. Clinical Psychology: Science and Practice, 8, 133-142.

Safren, S. A., Perlman, C. A., Sprich, S., \& Ott, W. (2005). Mastering your adult ADHD: A cognitive-behavioral treatment program therapist guide. New York, NY: Oxford University Press.

Scheithauer, M. C., \& Kelley, M. L. (2014). Self-monitoring by college students with ADHD: The impact on academic performance. Journal of Attention Disorders, 21, 1030-1039.

Smith, B. H., Barkley, R. A., \& Shapiro, C. J. (2006). Combined child therapies. In R. A. Barkley (Ed.), Attention-deficit/ hyperactivity disorder: A handbook for diagnosis and treatment (3rd ed.). New York, NY: Guilford Press.

Solanto, M. V. (2011). Cognitive-behavioral therapy for adult ADHD: Targeting executive dysfunction. New York, NY: Guilford Press.

Swartz, S. L., Prevatt, F., \& Proctor, B. E. (2005). A coaching intervention for college students with attention deficit/hyperactivity disorder. Psychology in the Schools, 42, 647-656.

Weinstein, C.E., \& Palmer, D.R. (2002). LASSI user's manual: For those administering the learning and studies strategies inventory (2nd edition). H \& H Publishing Company: Clearwater, FL.

Weyandt, L. L., \& DuPaul, G. J. (2012). Introduction to special series on college students with ADHD: Psychosocial issues, comorbidity, and treatment. Journal of Attention Disorders, 16, 199-201.

Weyandt, L. L., DuPaul, G. J., Verdi, G., Rossi, J. S., Swentosky, A. J., Vilardo, B. S., . . Carson, K. S. (2013). The performance of college students with and without ADHD: Neuropsychological, academic, and psychosocial functioning. Journal of Psychopathology and Behavioral Assessment, 35, 421-435.

Wolf, L. E., Simkowitz, P., \& Carlson, H. (2009). College students with attention-deficit/hyperactivity disorder. Current Psychiatry Reports, 11, 415-421.

\section{Author Biographies}

Arthur D. Anastopoulos, $\mathrm{PhD}$, received his doctorate in clinical psychology from Purdue University and currently holds the position of Professor in the Department of Human Development and Family Studies at the University of North Carolina at Greensboro, where he also directs a specialty ADHD Clinic. Throughout his career Dr. Anastopoulos has maintained clinical and research interests in the assessment and treatment of attention-deficit/ hyperactivity disorder (ADHD) across the life span, with a current focus on emerging adults with ADHD attending college.

Kristen A. King, PhD, completed her doctorate in clinical psychology from the University of Delaware. She is currently a Research Scientist in the Department of Human Development and Family Studies at the University of North Carolina at Greensboro, where she also performs work as a licensed psychologist in a specialty ADHD Clinic. Dr. King's clinical and research interests include the assessment and treatment of ADHD in college students, the development of emotion regulation skills in children, and program evaluation.

Laura H. Besecker, PhD, is a research scientist in the Department of Human Development and 
Family Studies at the University of North Carolina at Greensboro, where she completed her doctorate in clinical psychology. In addition to her clinical work within the ADHD Clinic, Dr. Besecker is the Director of the North Carolina Summer Program for Children. Dr. Besecker's clinical and research interests are focused on resilience and protective factors among youth with ADHD, anxiety, disruptive disorders, and health needs.

Sarah O'Rourke, PhD, is currently a medical instructor in the Department of Psychiatry and Behavioral Sciences at the Duke University School of Medicine. She completed her doctorate in clinical psychology at the University of North Carolina at Greensboro. Dr. O'Rourke's clinical and research interests include evidence-based assessment and treatment of youth with ADHD, anxiety disorders, and chronic health conditions.

Allison C. Bray, PhD, completed her doctorate in clinical psychology at the University of North Carolina at Greensboro and currently is a licensed psychologist in the behavioral medicine division at LeBauer Healthcare/Cone Health System in Greensboro, NC. Dr. Bray's clinical and research interests include the assessment and treatment of ADHD and comorbid depression and anxiety in youth and adults.

Andrew J. Supple, PhD, received his doctorate in Human Development and Family Studies from the University of Wisconsin. Dr. Supple currently holds the position of associate professor in the Department of Human Development and Family Studies at the University of North Carolina at Greensboro. His research interests include youth and adolescent development, cultural variations, research methods and program evaluation. 